\title{
The seminal coagulum favours passage of fast-moving sperm into the uterus in the black-handed spider monkey
}

\author{
Leonor Hernández-López, Ana Lilia Cerda-Molina, Denisse L Páez-Ponce \\ and Ricardo Mondragón-Ceballos \\ Departamento de Etología, Dirección de Neurociencias, Instituto Nacional de Psiquiatría Ramón de la Fuente Muñiz, \\ Calzada México-Xochimilco 101, Col. San Lorenzo Huipulco, Tlalpan 14370, Mexico D.F., Mexico \\ Correspondence should be addressed to R Mondragón-Ceballos; Email: rmc@imp.edu.mx
}

\begin{abstract}
In addition to gametes, mammalian internal fertilisation has required the evolution of assorted anatomical, physiological and biochemical devices to deal with intra- and inter-sexual conflict such as sperm competition and female cryptic choice respectively. The seminal coagulum of primates and other mammals is viewed as one of such devices. Among primates, the seminal coagulum characteristically occurs in multi-male and multi-female species, leading us to suppose that it intervenes in sperm competition. However, it can also provide cues to the female reproductive tract about male desired or undesired traits, and therefore deter or favour sperm survival and migration. The present work investigates whether the seminal coagulum of the black-handed spider monkey enhances sperm fertilisation chances by improving the female reproductive tract conditions, and if the female reproductive tract is 'blind' to semen or behaves selectively towards ejaculates of different males. A series of artificial inseminations were done in five females, using the ejaculates of three different males, one at a time, and measuring the presence of distinct types of sperm inside the uteri at 10, 30 and 60 min following the insemination. The presence of coagulum, menstrual phase, and male and female identity only affected fast, straightmoving sperm, with larger amounts of fast sperm appearing inside the uteri when ejaculates had seminal coagulum, as well as when in the periovulatory phase. There was great intra-uterine fast-sperm variation regarding which male's semen inseminated which female. The results provide evidence to account for sexual conflict in the spider monkey as well as a methodological approach to this kind of study. Reproduction (2008) 136 411-421
\end{abstract}

\section{Introduction}

In animal species with internal fecundation, fertilising involves more than a proper ejaculation in the female reproductive tract (Gomendio et al. 1998, 2007, Satake et al. 2006, Immler 2008). In particular, if contending males are able to deposit semen in the same female, in turn, the female requires control of the fate of the sperm deposited within its reproductive tract in order to enhance its own and offspring's fitness and override any reproductive costs inflicted by males. Such was the scenario in which post-copulatory male-male competition (Parker 1998, Birkhead \& Pizzari 2002) and female cryptic mate choice (Eberhard 1996, 1998) evolved. Therefore, in addition to ornaments and behaviour traits, females and males must evolve further anatomical, physiological and biochemical devices that account for such observed post-copulatory reproductive success (Eberhard 1996, 1998, Gomendio et al. 1998, Parker 1998, Birkhead \& Pizzari 2002, Immler 2008). Such events in most vertebrates, and particularly in mammals, take place within the female reproductive tract, requiring a physiological rather than a behavioural approach for their study.

Among male primates, the seminal coagulum produced by the prostate, the seminal vesicle and the bulbourethral glands is likely one of such devices (Dixson 1998). Comparative analyses on the presence or absence of seminal coagulum in the ejaculate of different mammal species suggest that this structure evolved mainly to deal with male-male competition (Dixson \& Anderson 2002, 2004). However, there is a possibility that the seminal coagulum also has a role in female cryptic choice. Such a view is supported by the fact that is a major trait showing variability (Sato et al. 2007, Hernández-López et al. 2008), providing females (or their reproductive tracts) a substrate for male quality assessment. Since different glands contribute to its formation, a small variation in the amounts of constituents contributed by each gland yields structurally diverse seminal coagula, where changes in its components, independently from sperm concentration, severely impair fertility (Rossato et al. 2002, Mikhailichenko \& Esipov 2005, Khosrowbeygi \& Zarghami 2007, de Lamiranda 2007). 
The first barrier met by spermatozoa on their way to fertilise oocytes is vaginal acidity, since an acid vaginal milieu immobilises and damages sperm (Carr et al. 1985, Boskey et al. 1999, 2001). The vaginal tract acidity of female mammals varies throughout the uterine cycle (Bauman et al. 1982, Dixson 1998, Boskey et al. 1999, 2001, Suarez \& Pacey 2006), depending on the fluctuations in steroid hormone levels and bacterial growth. As ovulation approaches, the vaginal $\mathrm{pH}$ becomes more acidic due to an increase in glycogen accumulation promoted by steroid hormones and by the conversion of glycogen to lactic acid by vaginal bacteria (Bauman et al. 1982, Papka \& Williams 1998, Boskey et al. 1999, 2001). By contrast, glycogen becomes less abundant and vaginal $\mathrm{pH}$ turns to neutral throughout the luteal phase (primates) or metestrus (other mammals) of the uterine cycle, due to the decrease in the levels of steroid hormones (Bauman et al. 1982, Papka \& Williams 1998, Boskey et al. 1999, 2001). Increased vaginal acidity throughout the periovulatory phase has been ascribed the function of protecting females against sexually transmitted disease (Castle et al. 2002, Olmsted et al. 2005). However, in most primates, sexual intercourse occurs throughout the entire menstrual cycle (Dixson 1998), leaving females at the risk of contracting a venereal disease at all times. Therefore, the acid periovulatory milieu could well be controlling the fate of the sperm deposited within the vaginal tract.

The seminal coagulum is slightly alkaline (7.2-8.0 in humans) and acts to neutralise vaginal acidity (Prins 1998), while ascorbic acid (Song et al. 2006) and L-carnitine (De Rosa et al. 2005) protect sperm DNA from denaturation. The seminal coagulum also provides a viscous matrix preventing sperm diffusion out of the ejaculate, and in many primate species contains semenogelins as well as prostate-specific antigen and prostatic acid phosphatase, the enzymes needed to induce ejaculate clotting and its further liquefaction respectively (Lilja 1993, Dorus et al. 2004, Clark \& Swanson 2005). In addition, semenogelins induce sperm quiescence to avoid spending energy during migration throughout the male tract (Robert \& Gagnon 1996, Cooper 1998, Rossato et al. 2002, de Lamiranda 2007). Furthermore, prostaglandins found in the seminal coagulum induce contractions of the smooth musculature of the female tract to enhance sperm transport (Prins 1998, Suarez \& Pacey 2006). All these add up to protect sperm from a hostile female environment, rather than merely obstruct sperm from other males. However, sperm migration up the female tract is not accomplished merely by sperm movement, but aided by vaginal, cervical and uterine contractions, and by cilia movement of the tract wall (Suarez \& Pacey 2006).

The black-handed spider monkey (Ateles geoffroyi) is considered a promiscuous species (Dixson 1998, Dixson \& Anderson 2002), although little is known of its sexual behaviour in the wild. Notwithstanding, relative testes size (Harcourt et al. 1981), as well as the presence of genes coding for enzymes promoting clotting and liquefaction of the seminal coagulum (Dorus et al. 2004, Clark \& Swanson 2005), supports the notion that post-copulatory sperm competition and female cryptic choice occur in this species. Unlike in man and chimpanzees (Lilja 1993, Dixson 1998), spontaneous in vitro liquefaction of the coagulum does not happen in the spider monkey (Hernández-López et al. 2002a, $2002 b$ ). Therefore, activation of the enzymes promoting liquefaction might be dependent on vaginal physicochemical cues, such as temperature or $\mathrm{pH}$ (Carr et al. 1985, Gundlach \& Luttermann-Semmer 1987, Rossato et al. 2002), or even complex biochemical interactions between the vaginal milieu and the ejaculate, such as enzyme-enzyme interactions. In any case, if coagulum liquefaction is required from the vaginal milieu, it is likely that females are able to control the fate of ejaculates within their reproductive tract, and thereby fertilisation by cues informing about male fitness, histocompatibility, etc., provided by this structure. The present work was done to investigate by means of artificial insemination $(\mathrm{Al})$ the in vivo role of the seminal coagulum in the supporting passage of diverse types of sperm from the vagina into the uterus, along with the part played by the vaginal milieu in such a promotion. We reasoned that coagulum dilution should be reflected in larger proportions of linearly motile spermatozoa inside the uterus, concomitant with a reduction in the percentage of immotile sperm. Since an acidic vaginal milieu immobilises and damages a sperm (Bauman et al. 1982), while coagulum alkalinity overturns it (Prins 1998), we compared sperm motility depending on whether or not the male emitted the seminal coagulum. We tested 1) whether ejaculates containing the coagulum show better pro-fertilising activity that when it is missing (Harper 1994) and 2) if liquefaction of the coagulum and types of sperm passing through the cervix into the uterus is dependent upon natural variation of local vaginal temperature or $\mathrm{pH}$. In other words, we expected to find inside the uteri greater proportions of straightforward-swimming sperm in the follicular and periovulatory phases of the menstrual cycle, when optimal fertilisation is more likely to occur. Finally, looking for evidence of individual female participation in the above-described issues, we tested 3) whether the types of sperm found in the uteri were related to the identity of the sperm donor.

\section{Results \\ Vaginal $\mathrm{pH}$ and temperature variations after and following $A I$}

Basal vaginal $\mathrm{pH}$ varied significantly throughout the menstrual cycle $\left(F_{2,38.13}=4.74, N=169, P=0.014\right)$; during the periovulatory phase it turned to be significantly 
$(P<0.05)$ more acidic (mean \pm S.E.M.: $6.5 \pm 0.09)$ than that in the luteal phase $(7.0 \pm 0.13)$, but not more than that in the follicular phase $(6.7 \pm 0.12)$. Basal vaginal temperature did not change throughout the menstrual phases (overall mean: $38 \pm 0.08{ }^{\circ} \mathrm{C}$ ). Semen $\mathrm{pH}$ did not vary, being always 8, whether or not the seminal coagulum was emitted. Vaginal temperature following AI was slightly but significantly colder when semen lacked seminal coagulum (coagulum absent: $37.2 \pm 0.12{ }^{\circ} \mathrm{C}$; coagulum present: $\left.37.8 \pm 0.1^{\circ} \mathrm{C} ; F_{1,33.14}=5.21, P=0.03\right)$, menstrual phase having no effect $\left(F_{2,26.69}=0.38, N=169, P=0.7\right)$. We found a vaginal $\mathrm{pH}$ turnover after performing the inseminations, related to both the menstrual cycle phase and coagulum incidence $\left(F_{2,24.67}=6.16, N=169\right.$, $P=0.007$ ). Irrespective of the presence or absence of seminal coagulum, semen always turned vaginal $\mathrm{pH}$ towards alkaline (follicular-periovulatory: $7.6 \pm 0.2$ ), except in the luteal phase, where $\mathrm{pH}$ turned to completely basic when the ejaculates lacked coagulum $(8.7 \pm 0.3)$, while those where the coagulum was present turned neutral $(7.2 \pm 0.2)$.

\section{Sperm migration}

Movement of sperm was classified into four types (Table 1). Excluding fast, linearly-moving sperm (FLM), there were no significant effects involving types of sperm collected within the uterus in relation to menstrual phase, coagulum incidence and time of collection. FLM occurrence through time significantly changed depending on whether the coagulum was present or absent and the menstrual phase $\left(F_{4,59.05}=3.76, \quad N=1014\right.$, $P=0.009$ ). As is appreciated in Fig. $1 \mathrm{~A}$, when the ejaculate contained seminal coagulum, FLM arrived earlier to the uterus, continuing to do so up to $30 \mathrm{~min}$ past the insemination in the periovulatory phase. An hour after the insemination, few FLM were collected from the uteri. In contrast, similar inseminations performed in other menstrual phases showed different time patterns. In the follicular phase, FLM arrival increased at $30 \mathrm{~min}$ following the insemination, extending up to $1 \mathrm{~h}$ after the insemination. In the luteal phase, few FLM were collected at all times. Different patterns of intra-uterine FLM occurred when the semen lacked coagulum (Fig. 1B). Seemingly, the FLM arrival was

Table 1 Classification of sperm according to its movement.

\begin{tabular}{lcl}
\hline $\begin{array}{l}\text { Description of sperm } \\
\text { movement }\end{array}$ & $\begin{array}{c}\text { Classification used in } \\
\text { the present paper } \\
\text { (abbreviation) }\end{array}$ & $\begin{array}{c}\text { WHO } \\
\text { classification }\end{array}$ \\
\hline $\begin{array}{c}\text { Fast, directed forward } \\
\text { movement }\end{array}$ & $\begin{array}{c}\text { Fast, linearly-moving } \\
\text { sperm (FLM) }\end{array}$ & $3,3+, 4$ \\
$\begin{array}{c}\text { Slow, directed forward } \\
\text { movement }\end{array}$ & $\begin{array}{c}\text { Slow, linearly-moving } \\
\text { sperm (SLM) }\end{array}$ & $2+$ \\
$\begin{array}{c}\text { Undirected movement, } \\
\text { irrespective of velocity }\end{array}$ & $\begin{array}{c}\text { Non-linear movement } \\
\text { (NLM) }\end{array}$ & $1,2,3-$ \\
$\begin{array}{c}\text { Mostly no movement } \\
\text { Immotile sperm (IMM) }\end{array}$ & $0,1+$ \\
\hline
\end{tabular}
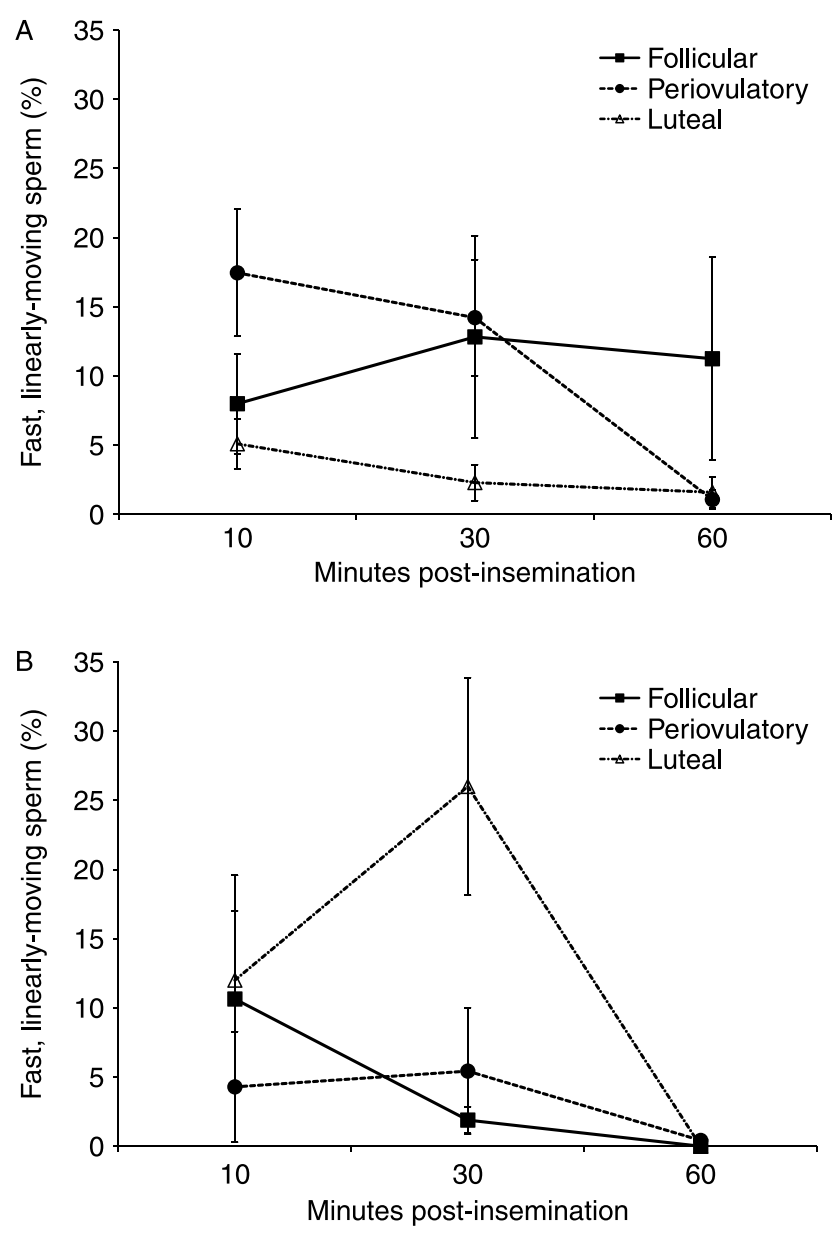

Figure 1 Mean ( \pm S.E.M.) percentage of FLM collected from the uteri at 10, 30 and 60 min following artificial inseminations done in follicular, periovulatory and luteal phases of female black-handed spider monkeys. (A) Inseminations done with semen containing seminal coagulum. (B) Inseminations done with semen lacking seminal coagulum.

greater in the luteal phase, particularly at 30 min past the insemination. However, a single insemination was responsible for such an increase at $30 \mathrm{~min}$; removing this value returns the FLM values to averages observed in other menstrual phases (3.6 $\pm 3.3 \%)$. Although at $10 \mathrm{~min}$ the mean number of intra-uterine-collected FLM was not much different from that when inseminations included the seminal coagulum, the large variation suggests a random rather than a coordinated release and migration.

Concerning other types of sperm, immotile sperm (IMM) showed a trend to vary in relation to menstrual phase and coagulum incidence $\left(F_{2,40.98}=3.02\right.$, $N=1014, P=0.06$ ). When the coagulum was present, intra-uterine IMM occurred less in the periovulatory $(39.4 \pm 8.03 \%)$ than that in the follicular $(49 \pm 10.38 \%)$ and luteal $(55.53 \pm 10.33 \%)$ phases. Contrastingly, in the absence of coagulum, more IMM appeared in the periovulatory phase $(60.10 \pm 8.43 \%)$ than in the follicular $(57.05 \pm 12.97 \%)$ phase, while decreasing in the luteal phase $(27.45 \pm 13.91 \%)$. Although both 
slow, linearly-moving sperm (SLM) and non-linearlymoving sperm (NLM) were recovered from the uteri at constant rates (SLM: $16.57 \pm 1.74 \%$; NLM: $22.91 \pm 1.80 \%$ ), their occurrence was unrelated to coagulum incidence or menstrual phase.

\section{Effects of vaginal $\mathrm{pH}$ and temperature on sperm migration}

Only the multiple regression between mean intra-uterine FLM and $\mathrm{pHs}$ and temperatures in ejaculates having seminal coagulum accounted for a significant linear relationship $\left(F_{4,90}=3.3, R^{2}=0.12, P=0.014\right)$. Table 2 shows the results for this multiple regression. Postinsemination vaginal $\mathrm{pH}$ and post-insemination temperature exerted significant effects, but not basal $\mathrm{pH}$ and temperature. Figure 2 shows the scatterplots and the partial residual plots for the intra-uterine FLM against post-insemination $\mathrm{pH}$ and temperature. The average FLM collected from the uteri increased significantly as vaginal $\mathrm{pH}$ turned from acid to alkaline and temperature became warmer. Notice that despite the significant linear relationships yielded by the multiple regression analysis, data are quite scattered. An outlier point for postinsemination $\mathrm{pH}$ and two for post-insemination temperature were detected (boxed data points in Fig. 2). Yet, dropping these cases out from the analyses marginally reduced the relationship between the FLM and postinsemination $\mathrm{pH} \quad\left(\beta \pm\right.$ s.E. $=6.87 \pm 3.43, t_{92}=2.0$, $P=0.05)$, while increasing that with temperature $\left(\beta \pm\right.$ s.E. $\left.=6.18 \pm 2.3, t_{91}=2.69, P=0.008\right)$. Although the examination of the P-P plot showed a fair adjustment of FLM to a normal distribution, data points in Fig. 2 do not really align in linear trends. In Fig. $2 \mathrm{~A}$ and $\mathrm{B}$, two populations of FLM are apparent, the first one is a population that does not appear to respond to vaginal $\mathrm{pH}$ turnover, either not appearing inside the uteri or doing so at low rates $(0-10 \%$ in Fig. $2 \mathrm{~A}$; residual values $40-60$ in 2B). The other population includes a hump-shaped scattering of data points when $\mathrm{pH}$ varied from 7.5 to 9 .
This latter population seems to correspond to $\mathrm{pH}$ responsive FLM, showing that passage to the uterus is facilitated at a vaginal $\mathrm{pH}$ around 7.3 , is maximal at 8 , and decreases as the vagina turns much more basic. A similar situation is seen concerning vaginal temperature; once more there is a collection of data points accounting for no intra-uterine occurrence of FLM or doing so at low proportions regardless of temperature variation $(0-10 \%$ in Fig. 2C; residual values $180-190$ in Fig. 2D). The remaining FLM data points, predominantly appearing above the regression line, show a somewhat clear tendency to augment inside the uteri as vaginal temperature increases. It is worth remembering that these vaginal $\mathrm{pH}$ and temperatures are local modifications produced by coagulum-containing ejaculates. When ejaculates lacked coagulum, the multiple regression also yielded a significant effect for the intrauterine $\operatorname{FLM}\left(F_{4,70}=5.73, R^{2}=0.23, P=0.0005\right)$, but not for any other type of sperm motility. Basal vaginal $\mathrm{pH}$ and post-insemination temperature were the variables contributing significantly to intra-uterine variation of FLM, while post-insemination vaginal $\mathrm{pH}$ and basal temperature did not do so (Table 2). Figure 3 shows the scatterplots and partial residual plots for these results. Besides being less abundant than when ejaculates had seminal coagulum, the intra-uterine FLM decreased as basal vaginal $\mathrm{pH}$ went from neutral to basic (Fig. 3A and B). On the other hand, the effect of post-insemination temperature was the same as when ejaculates contained seminal coagulum, intra-uterine FLM arrival increasing as the vagina turned warmer (Fig. 3C and D). Removing two outliers (boxed data points in Fig. 3) from the analysis did not greatly affect the results (basal $\mathrm{pH}: \beta \pm$ s.E. $=-2.89 \pm 0.42$, $t_{68}=-6.97, P<0.0001$; post-insemination temperature: $\beta \pm$ s.E. $=1.45 \pm 0.32, t_{68}=4.54, P<0.0001$ ). However, the large unexplained variance in both the entire linear model and the partial correlations of $\mathrm{pH}$ and temperature (Table 2), as well as the number of times no FLM was found inside the uteri (zero values in Fig. 2), suggests that males are not entirely responsible for FLM passage through the cervix.

Table 2 Multiple regression coefficients for intra-uterine collected fast, linearly-moving (FLM) in female black-handed spider monkeys in relation to basal and post-insemination $\mathrm{pH}$ and temperature in ejaculates having or lacking seminal coagulum.

\begin{tabular}{|c|c|c|c|c|c|c|}
\hline Variable & $\beta$ & Standard error & Partial correlation & $t$ & d.f. & $\boldsymbol{P}$ \\
\hline \multicolumn{7}{|l|}{ Ejaculates having seminal coagulum } \\
\hline Basal vaginal pH & -4.39 & 3.64 & -0.12 & -1.21 & 90 & 0.230 \\
\hline Basal vaginal temperature & 1.01 & 4.51 & 0.02 & 0.22 & 90 & 0.820 \\
\hline Post-insemination vaginal $\mathrm{pH}$ & 9.15 & 3.54 & 0.26 & 2.58 & 90 & 0.011 \\
\hline Post-insemination vaginal temperature & 5.33 & 2.73 & 0.20 & 1.96 & 90 & 0.053 \\
\hline Constant & -262.45 & 159.17 & & & & \\
\hline \multicolumn{7}{|l|}{ Ejaculates lacking seminal coagulum } \\
\hline Basal vaginal $\mathrm{pH}$ & -2.89 & 0.42 & -0.63 & -6.97 & 70 & 0.001 \\
\hline Basal vaginal temperature & -0.38 & 0.51 & -0.08 & -0.75 & 70 & 0.457 \\
\hline Post-insemination vaginal $\mathrm{pH}$ & 0.23 & 0.41 & 0.06 & 0.56 & 70 & 0.575 \\
\hline Post-insemination vaginal temperature & 1.45 & 0.32 & 0.46 & 4.54 & 70 & 0.025 \\
\hline Constant & -19.43 & 17.60 & & & & \\
\hline
\end{tabular}



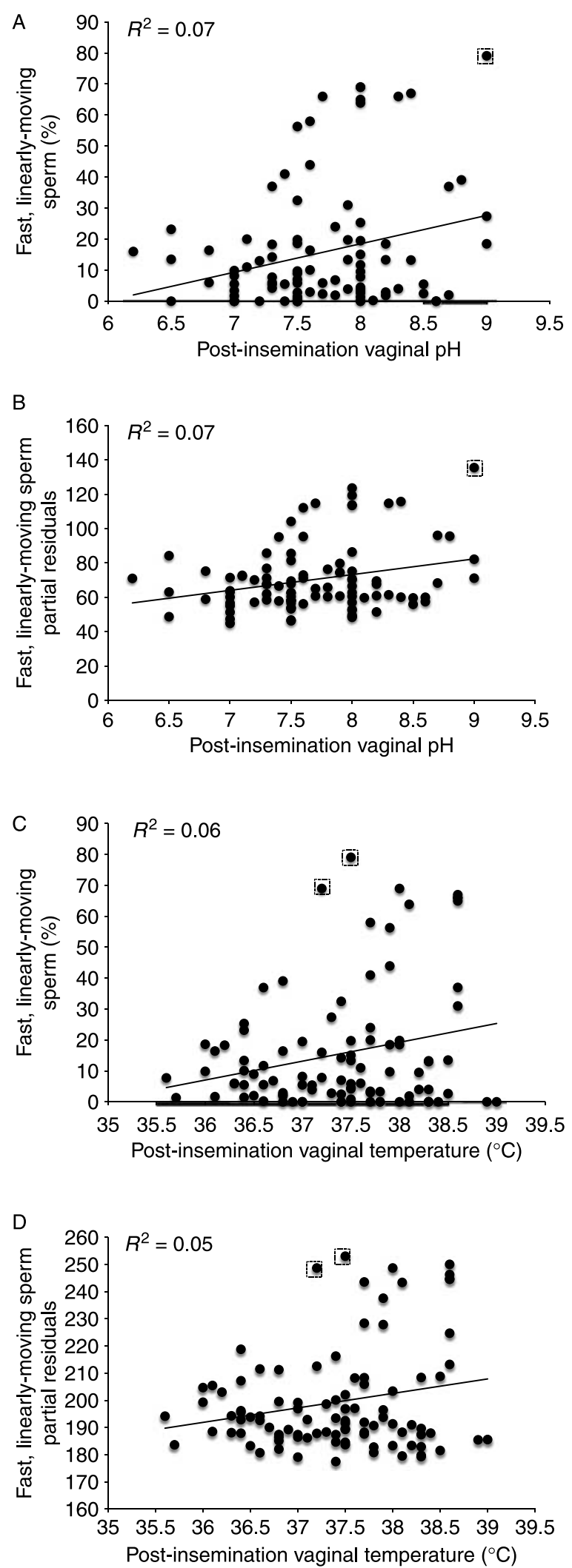

Figure 2 Scatterplots and partial residual plots of mean percentages of intra-uterine collected FLM as a function of post-insemination vaginal ( $\mathrm{A}$ and $\mathrm{B}$ ) $\mathrm{pH}$ and ( $\mathrm{C}$ and $\mathrm{D}$ ) temperature following artificial inseminations with ejaculates having seminal coagulum.

\section{Males and females identity effects}

Again, apart from FLM and IMM in the periovulatory phase, results from analysing the males, females and males within females as fixed effects showed no significant variations. Significant variation during the periovulatory phase in FLM was associated with which male's semen was used to inseminate each female, as well as to the presence or absence of seminal coagulum $\left(F_{1,38}=11.54, N=87, P=0.002\right)$. Table 3 shows the mean distribution of the intrauterine-collected FLM in the $\mathrm{Al}$ performed in the periovulatory phase in relation to male and female identities, and whether ejaculates had or lacked seminal coagulum. Depending on which male's semen was used to inseminate which female, if coagulum was present, mean FLM varied from 3.2 to $53.5 \%$ and when it was absent, from 0 to $45.6 \%$. In accordance with the above-mentioned results, a larger passage of FLM occurred when the coagulum was present. Even though FLM from one male, LK, was apparently more abundant, there were no between-male differences $\left(F_{2,38}=1.57, P=0.22\right)$, between-female differences $\left(F_{4,38}=1.06, \quad P=0.4\right)$ and the significant male-female interaction got lost if the effect of coagulum incidence was not included $\left(F_{3,38}=2.10, P=0.12\right)$.

Besides FLM, IMM in the periovulatory phase also varied significantly in relation to male and female identities $\left(F_{4,38}=2.88, \quad N=87, P=0.035\right)$, this time irrespective of coagulum incidence, ranging from 12.7 to $67.5 \%$ (Table 4). However, there was significant between-male variation $\left(F_{2,38}=7.93, P=0.0013\right)$, where the IMM values of KI were significantly larger (post hoc contrasts: $P<0.05$ ) than those of the other two males. Moreover, including all male values, FLM and IMM were significantly and negatively correlated $\left(r_{s}=-0.53, N=45, P<0.001\right)$.

\section{Discussion}

Although far from being conclusive, our results give evidence of sexual conflict in the black-handed spider monkey. Similar to other mammals studied so far (see Introduction), the vagina of the female spider monkey is hostile to sperm, particularly around the time of ovulation, when it is quite acidic. The sperm of the spider monkey is fairly labile; just a drop of urine in the ejaculate or cold room temperature (below $25^{\circ} \mathrm{C}$ ) is enough to massively kill spermatozoa (L Hernández-López, AL Cerda-Molina \& R Mondragón-Ceballos, unpublished results). Our results show that seminal coagulum not only adequately alkalinises vaginal $\mathrm{pH}$ in follicular and periovulatory phases, when fertilisation is likely to happen, but also keeps a satisfactory vaginal temperature, perhaps preventing sperm from thermal shock. Changing to a basic milieu favours spermatic motility in the fertile phases of the female (Bauman et al. 1982, Carr 

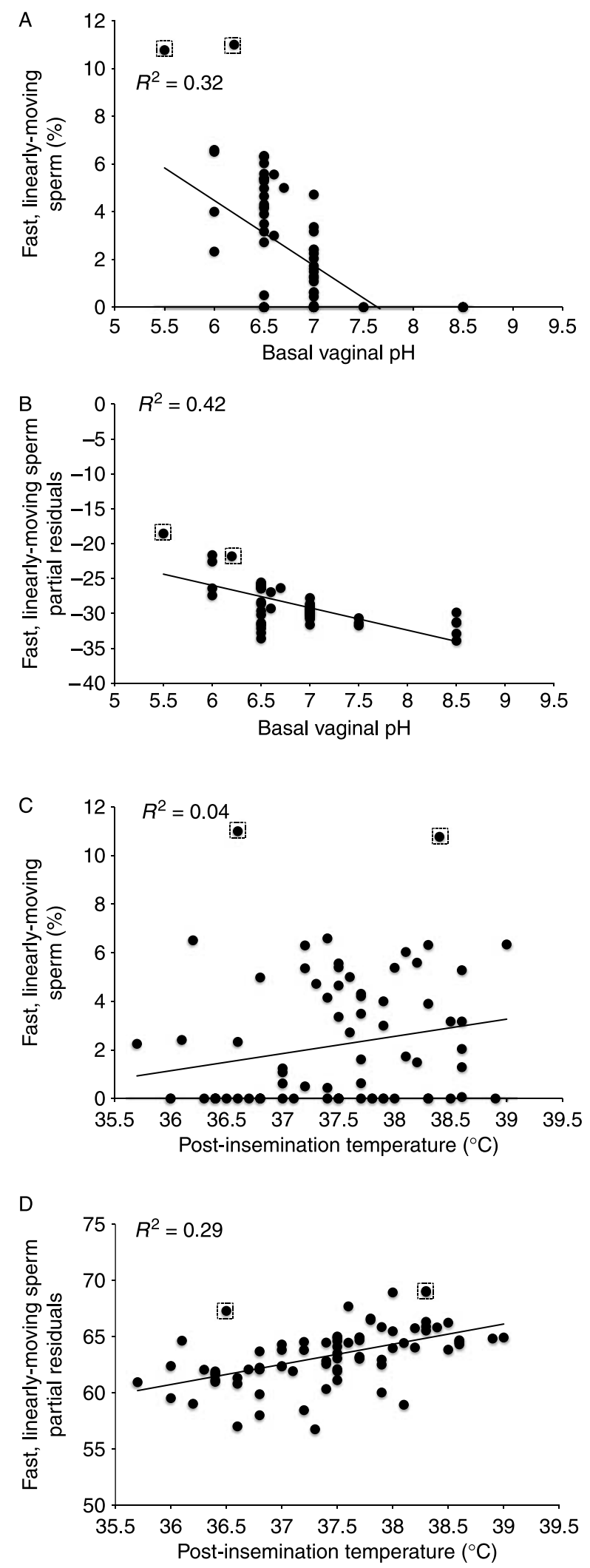

Figure 3 Scatterplots and partial residual plots of mean percentages of intra-uterine collected FLM as a function of basal vaginal (A and $B) \mathrm{pH}$ and (C and $\mathrm{D}$ ) post-insemination temperature following artificial inseminations with ejaculates lacking seminal coagulum. et al. 1985). However, the opposing effects of ejaculates having and lacking seminal coagulum in the luteal phase suggest additional female participation in the acidity turnover rather than a pure effect of semen. Otherwise, as semen $\mathrm{pH}$ was invariant, expectedly the same turnover would occur in each menstrual phase. It is not known whether in natural conditions emission of seminal coagulum occurs at all times in this species, and it certainly can be an electroejaculation artefact. However, for the purposes of the present work, such variability in seminal coagulum emission provided a control to contrast the putative functions of the coagulum.

The spider monkey is absolutely arboreal (Estrada et al. 2004), only rarely venturing to the ground (Campbell et al. 2005). Therefore, seminal coagulum might serve to prevent sperm loss from the vagina or flow back (Baker \& Bellis 1993). However, our results show that as in other mammals (reviewed in Suarez \& Pacey 2006), seminal coagulum promotes sperm passage through the cervix into the uterus, specifically in case of straightforwardmoving sperm during the periovulatory phase. The timed intra-uterine appearance of FLM suggests a paced release from the coagulum as well as transiting through the uterus, rather than getting stored in it. By contrast, when the ejaculates lacked seminal coagulum, FLM intra-uterine arrival was erratic and inappropriate, sometimes appearing in unusually large proportions in the luteal phase (Fig. 1b), which is certainly not the most suitable time for an optimal fertilisation.

The unvarying intra-uterine presence through all menstrual phases, disregarding the presence or absence of seminal coagulum, of SLM, NLM and to some extent IMM, is likely owing to their being massively moved upward by contractions induced by constituents of the ejaculate, whereas FLM released from the seminal coagulum seemingly swam through the cervix in the periovulatory phase, when the cervical canal conditions were fit to allow such a passage (Suarez \& Pacey 2006). The finding that the total intra-uterine FLM was positively correlated with the amount of vaginal alkalinisation and warming induced by ejaculates having seminal coagulum, but not, at least concerning post-insemination $\mathrm{pH}$, when the coagulum was absent, gives further support to the idea of FLM being released from the coagulum and swimming through the cervix. However, the tendency of IMM to decrease in the periovulatory phase when the seminal coagulum was present, as well as the negative correlation with FLM, suggests that either additionally or alternatively the FLM were released in utero from the seminal coagulum.

Although the results described above support the fact that seminal coagulum induces vaginal modifications favourable to FLM passage through the cervix, the findings of what appear to be two populations of FLM, one increasing along with post-insemination $\mathrm{pH}$ and temperature, and another one irresponsive to these 
Table 3 Mean (S.E.M.) percentages of intra-uterine collected fast linear-moving (FLM) following artificial inseminations of female black-handed spider monkeys performed in the periovulatory phase according to which male's semen was used to inseminate each female.

\begin{tabular}{|c|c|c|c|c|c|c|c|c|c|}
\hline \multirow[b]{3}{*}{ Female } & \multicolumn{9}{|c|}{ Male } \\
\hline & \multicolumn{3}{|c|}{$\mathrm{AD}$} & \multicolumn{3}{|c|}{$\mathrm{KI}$} & \multicolumn{3}{|c|}{ LK } \\
\hline & Mean & S.E.M. & $N^{a}$ & Mean & S.E.M. & $N$ & Mean & S.E.M. & $N$ \\
\hline \multicolumn{10}{|c|}{ Coagulum present } \\
\hline$A R$ & 3.4 & 2.9 & 3 & 9.3 & 5.0 & 3 & 21.0 & 7.1 & 3 \\
\hline $\mathrm{Cl}$ & 19.3 & 5.7 & 4 & 17.6 & 7.5 & 3 & 36.7 & 9.3 & 4 \\
\hline FR & 7.4 & 4.7 & 3 & 13.4 & 7.1 & 3 & 36.1 & 9.2 & 3 \\
\hline LE & 36.3 & 9.1 & 3 & 15.9 & 8.8 & 3 & 10.0 & 9.1 & 3 \\
\hline LO & 3.2 & 5.4 & 3 & 15.5 & 8.4 & 3 & 53.5 & 11.2 & 3 \\
\hline \multicolumn{10}{|c|}{ Coagulum absent } \\
\hline$A R$ & 1.6 & 6.4 & 2 & 5.8 & 5.6 & 3 & 15.6 & 5.3 & 3 \\
\hline $\mathrm{Cl}$ & 2.0 & 6.5 & 3 & 3.6 & 5.7 & 3 & 3.5 & 3.5 & 3 \\
\hline FR & 3.2 & 6.5 & 3 & 3.0 & 5.0 & 3 & 0.0 & & 1 \\
\hline LE & 1.2 & 4.5 & 2 & 7.6 & 6.4 & 3 & 45.6 & 13.1 & 3 \\
\hline LO & 0.8 & 6.4 & 2 & 3.6 & 5.5 & 3 & 3.3 & 9.0 & 3 \\
\hline
\end{tabular}

${ }^{\mathrm{a}}$ Number of inseminations done per female (rows) using the semen of each male (columns).

variations, provide evidence that such migration is not utterly provoked by the male (or the seminal coagulum), but that females are also able to exert control on the crossing of FLM through the cervical canal. The intrauterine FLM patterning in relation to male and female identities and its negative correlation with IMM credit the latter conclusion by showing enhanced (or lessened) FLM activity, in certain male-female combinations.

Aside from its supposed role in sperm competition (Dixson \& Anderson 2002, 2004), the present results acknowledge that the seminal coagulum might have evolved to deal with inter-sexual conflict. Therefore, besides maintaining spermatozoa in a quiescent state while passing from the testicles to the vagina (Carr et al. 1985, Khosrowbeygi \& Zarghami 2007), the seminal coagulum turns the female vagina into an appropriate environment for sperm survival and migration (Carr et al. 1985). However, this is not entirely accomplished by the male, requiring female participation. Although still far from being compelling evidence of female cryptic choice in the spider monkey, our results acknowledge that sperm selection starts as early as the vagina, where females seemingly rely on cues provided by the seminal coagulum in favouring or opposing FLM migration.
It is noteworthy that we found no differences between males in the proportions of different types of sperm collected within the uteri, except for a significant larger percentage of IMM in one male. This contrasts with whole ejaculate evaluations where we repeatedly and consistently found significant between-male differences in both sperm concentration and proportions of sperm showing different motility (Hernández-López et al. 2002a, 2002b), but is consistent with the view that whole ejaculate assessment does not accurately reflect spermatic in vivo performance or fertility (Satake et al. 2006, Lewis 2007).

Fast, straight-swimming spermatozoa are related to fertility in other mammals (Olds-Clarke 1996, Malo et al. 2005, Satake et al. 2006, Gomendio et al. 2007), although such a relationship may not be so forthright as proposed by some authors viewing males with faster sperm as having greater chances of siring more offspring because these may be able to reach the ovum first (Malo et al. 2005, Gomendio et al. 2007). Sperm migration up the female reproductive tract is not accomplished solely by its motion, it is aided by components found in the seminal plasma and requires female assistance, such as the presence of highly hydrated cervical mucus and contractions of the uterine smooth muscle, which in turn

Table 4 Mean (S.E.M.) percentage of intra-uterine immotile sperm (IMM) following inseminations performed during the periovulatory phase of blackhanded spider monkeys according to which male's semen was used to inseminate each female.

\begin{tabular}{|c|c|c|c|c|c|c|c|c|c|}
\hline \multirow[b]{3}{*}{ Female } & \multicolumn{9}{|c|}{ Male } \\
\hline & \multicolumn{3}{|c|}{$A D$} & \multicolumn{3}{|c|}{$\mathrm{KI}$} & \multicolumn{3}{|c|}{ LK } \\
\hline & Mean & S.E.M. & $N$ & Mean & S.E.M. & $N$ & Mean & S.E.M. & $N$ \\
\hline AR & 45.2 & 7.6 & 5 & 51.3 & 12.3 & 6 & 50.8 & 14.4 & 3 \\
\hline $\mathrm{Cl}$ & 30.6 & 7.2 & 7 & 12.7 & 12.7 & 6 & 67.5 & 8.6 & 7 \\
\hline FR & 29.6 & 6.8 & 6 & 21.6 & 16.0 & 6 & 64.0 & 8.0 & 4 \\
\hline LE & 41.1 & 6.2 & 5 & 72.5 & 20.5 & 6 & 40.6 & 6.3 & 6 \\
\hline LO & 51.9 & 8.1 & 5 & 93.5 & 3.5 & 6 & 28.4 & 6.6 & 6 \\
\hline
\end{tabular}


can be additionally stimulated by constituents of the seminal plasma (Prins 1998, Suarez \& Pacey 2006). Recent experiments (Satake et al. 2006) showed that in boars there is a subpopulation of fast forward-moving spermatozoa highly and positively responsive to the female milieu, able to swim mainly on their own past the cervix and uterus. However, in all the mammals so far studied, including humans, their results being therefore very likely to be the same in other primates, most sperm will get trapped and immobilised in and past the uterotubal junction, which is both a physical (Suarez \& Pacey 2006) and chemical (Satake et al. 2006) barrier. In rabbits, the majority of these sperm are non-fertile, perhaps getting mortally damaged while being massively transported by uterine contractions (Overstreet \& Cooper 1978, Scott \& Overstreet 1998). Only a sub-subpopulation of the original ejaculate, spermatozoa having certain surface proteins besides the straight forceful motility, is able to traverse the uterotubal junction (Suarez \& Pacey 2006, Suarez 2007), to be stored in the isthmus and to undergo capacitation and hyperactivation to finally reach the ampulla (Suarez \& Pacey 2006, Rodriguez-Martinez 2007); all these involve both female and male participation. Likewise, it is not feasible to regard fast sperm in this work as utterly responsible for fertilisation in the spider monkey. Our results so far only acknowledge an initial selection of fast-swimming sperm past the cervix, which will still be subjected to even harsher selection upon reaching the oviduct (e.g. Satake et al. 2006). This subpopulation could well stand for the so-called vanguard sperm required to induce profertilising changes in the upper female tract (Scott \& Overstreet 1998, Suarez \& Pacey 2006), whereas fertilisation is achieved either by one among those of a sub-subpopulation reaching the ampulla or by latecoming spermatozoa. Nonetheless, our work gives credit to the idea that spider monkeys can adjust locally their reproductive physiology to contend with promiscuity, as occurs in other animal species (Devine 1977, Donald \& Dewsbury 1988, Parga 2003).

\section{Materials and Methods}

\section{Subjects}

Five female and three male adult black-handed spider monkeys (A. geoffroyi) were used. These monkeys, along with three additional females, live in a large outdoor facility in the Department of Ethology, Instituto Nacional de Psiquiatría Ramón de la Fuente Muñiz, in Mexico City. The monkeys are exposed to ambient conditions (i.e. temperature, humidity, photoperiod), fed Monkey Diet 5038 Lab Diet (PMI Feeds, Inc., St Louis, MO, USA), as well as fresh fruits and vegetables, and have ad libitum access to tap water. Cages are washed daily from 0800 to $0900 \mathrm{~h}$.

\section{Ethics of experimentation}

The Bioethics Committee of the Instituto Nacional de Psiquiatría Ramón de la Fuente Muñiz approved the experimental protocol and animal handling. We also followed the Mexican Official Norm of Technique Specifications for the Production, Care and Use of Laboratory Animals (NOM-062ZOO 1999), and the Policy Statement on Use of Primates for Biomedical Purposes, as adopted by the World Health Organization (WHO) and the Ecosystem Conservation Group.

\section{Assessment of menstrual cycles}

The phase of the menstrual cycle was determined by cytological examination. To collect vaginal swabs, the females were trained to enter a wire mesh cage $(1 \times 1 \times 1.5 \mathrm{~m})$ attached to the entrance of the outdoor enclosure, and allow the introduction of a cotton swab into the vagina. For their cooperation, they were rewarded with a marshmallow or small cookies. Vaginal smears were fixed in $96 \%$ ethanol for $10 \mathrm{~min}$, and stained using Shorr's Trichromic technique (Hernández-López et al. 1998). The menstrual phases (menses, follicular, periovulatory and luteal) were recognised depending on the proportional presence of four types of epithelial cells (scales, superficial, intermediate and parabasal), in addition to the presence of cervical mucus, erythrocytes and lymphocytes (Hernández-López et al. 1998).

\section{Semen collection}

Semen samples were collected by electroejaculation, as described previously (Hernández-López et al. 2002b). Briefly, the males were anaesthetised with ketamine chlorohydrate $(10$ mg/kg im; Anestek; CpMAX S.A. de C.V. de Mexico, D.F., Mexico); a rectal probe (12.5 $\mathrm{mm}$ in diameter, $9 \mathrm{~cm}$ long), previously lubricated ( $\mathrm{K}-\mathrm{Y}$ Líquido; Johnson \& Johnson, Indústria e Comércio LTDA., Sao Paulo, SP, Brazil), was introduced into the rectum $(\sim 5 \mathrm{~cm}$ deep), and electrical stimuli were delivered. A round of stimuli (starting at $1 \mathrm{~V}$ and $\approx 0.1 \mathrm{~mA}$ ) consisted of ten electric stimulations, each one lasting $10 \mathrm{~s}$, followed by a 5-s resting period. In successive rounds of stimulation, voltage and current were increased (in increments of $1.0 \mathrm{~V}$ and $0.1 \mathrm{~mA}$ respectively) until ejaculation occurred. Simultaneously, the penis was manually stimulated. The entire procedure took no more than $15 \mathrm{~min}$ (in the absence of ejaculation after $15 \mathrm{~min}$, the procedure was stopped).

\section{Experimental procedure}

A replicate consisted of electroejaculation, intra-vaginal $\mathrm{Al}$, and the subsequent recovery of sperm (from the uterus) and its evaluation. Early in the morning (0700-0800 h), one male and one female were removed from their pens. Both the monkeys were anaesthetised (ketamine chlorohydrate, $10 \mathrm{mg} / \mathrm{kg} \mathrm{im}$ ), and placed side by side on a surgical bed, with the male lying on his back and the female lying face downward, with her pelvis resting on a pillow (to elevate it). The penis of the male and the perineum of the female were cleaned with cotton (soaked in warm water), and allowed to dry. Thereafter, 
electroejaculation was done; and semen was collected in a $50 \mathrm{ml}$ sterilised polypropylene conical centrifuge tube (largest diameter, $1 \mathrm{~cm}$; length, $6 \mathrm{~cm}$ ), from which the tip had been removed. The centrifuge tube, tip downwards, was inserted into the vagina, until it reached the cervix. The semen was allowed to drain by gravity. A human Al intra-uterine cannula (Laboratoire C.C.D., Paris, France) was passed through the cervix and suction applied to recover sperm from the uterus at 10, 30 and $60 \mathrm{~min}$ after completing Al. The timing of semen collection was based on the rate of progression of sperm $(\sim 5 \mathrm{~mm} / \mathrm{min})$ and the length of a spider monkey cervix ( 30 mm; L Hernández-López, AL Cerda-Molina \& $\mathrm{R}$ Mondragón-Ceballos, unpublished data). We did not inseminate the same number of spermatozoids per male, as is usual in this kind of experiment (Malo et al. 2005, Satake et al. 2006), because except by using trypsin (Hernández-López et al. $2002 a$ ) it is not possible to dilute the seminal coagulum, and it does not dilute spontaneously outside the vagina. Trypsin severely impairs sperm; to dilute and therefore wash the ejaculate was precluded, since once outside the seminal coagulum, the spider monkey's sperm becomes extremely labile to temperature changes.

While performing the electroejaculation, the ejaculate was classified according to the visual presence or absence of seminal coagulum and a sample microscopically examined to assess the viability of the sample ( $>50 \%$ of live sperm). Sperm assessment was done by one of the experimenters, while the others proceeded with the $\mathrm{Al}$ in order to replicate, as closely as possible, intra-vaginal deposition of semen by natural mating. Consequently, some ejaculates classified as lacking seminal coagulum could have contained small amounts of this fraction.

Upon finishing intra-uterine semen sampling, a rapid clinical evaluation of the male was done, checking for rectal haemorrhage and assessing cardiovascular and respiratory functions. A similar evaluation was done on the females (with assessment for vaginal haemorrhage) $30 \mathrm{~min}$ after Al. The monkeys were placed in a $1 \times 1 \times 1 \mathrm{~m}$ stainless steel cage to allow them to recover, and afterwards they were fed and returned to their outdoor enclosure. For 7 days after semen collection and $\mathrm{Al}$, the monkeys were checked daily for general health and behaviour.

Al were done in the early follicular (days 3-5 of a 26-day menstrual cycle), periovulatory (days 8-12) and late luteal phases (days 23-25), with the idea of performing at least two inseminations per menstrual phase per female per male using ejaculates having seminal coagulum, and an equal number using semen lacking coagulum. This was not achieved because two females got pregnant almost at the end of experiments (October and November 2005 respectively) and were not further used. Around three Al were done weekly, using different male-female combinations until accomplishing 169 replicates (October 4, 2004 to December 16, 2005). Each male was electroejaculated at most once every 7 days; similarly, we inseminated each female no more often than once every 7 days. Ninety-four ejaculates had seminal coagulum, while 75 did not, distributed as follows: $20 \mathrm{Al}$ in the follicular, 47 in the periovulatory and 27 in the luteal phases using ejaculates having coagulum; $20 \mathrm{Al}$ in the follicular, 40 in the periovulatory and 15 in the luteal phases using semen lacking coagulum.

\section{Sperm evaluation}

From the each semen sample collected from the uterus, we took two $10 \mu \mathrm{l}$ aliquots to evaluate sperm motility. Following the WHO (1992) guidelines, we assessed the quantity and quality (movement) of sperm as shown in Table 1, since this method also has proven useful in non-human primates (Gago et al. 1999). We categorised sperm movement into four types: FLM, SLM, NLM and IMM. We reduced WHO motility classification to decrease the number of independent statistical analyses and because otherwise FLM was split into three categories, each comprising very small proportions of sperm. We assessed motility by counting 100 sperm twice, once in each $10 \mu \mathrm{l}$ aliquot. If the average difference between both counts exceeded 5\%, we took two new aliquots to assess.

\section{Statistical analyses}

We planned the experiment to collect data from 15 consecutive menstrual cycles per female (the average cycle in the spider monkey is around 26 days: Hernández-López et al. 1998), performing three inseminations per cycle (in the follicular, periovulatory and luteal phases), each using the semen of one of the three males. These would allow performing 45 inseminations per female, where each male's semen was used three times per menstrual phase. From such a procedure, we would end with a balanced design consisting of 225 data points (three inseminations/menstrual phase/male/female). However, we knew beforehand that ejaculation (or not) of the seminal coagulum is somewhat random and that most likely we would be unable to collect a balanced sample of ejaculates having and lacking coagulum where, besides the incidence of seminal coagula, all males, females and menstrual phases were at least proportionally, if not absolutely, represented. In addition, 48 inseminations, either because they consisted of entirely dead spermatozoids $(n=41)$ or the male did not electroejaculate in at most $15 \min (n=7)$, were not used in analyses, and ten more samples were not obtained because two females got pregnant when the experiments were almost finished. Thus, we ended with an unbalanced design matrix difficult to analyse by conventional parametric or non-parametric tests. Thus, we used general linear mixed models, employing restricted maximum-likelihood estimation (McCulloch \& Searle 2001), to analyse the data, given the small number of subjects studied, their repeated sampling and the unbalanced design due to discarding some samples. We used the Shapiro-Wilk test to determine the normality of response variables: percentages of FLM, SLM, NLM and IMM collected inside the uteri, and pre- and post-insemination vaginal $\mathrm{pH}$ and temperature. Temperature and $\mathrm{pH}$ were normally distributed, but sperm motility categories were not; thus, motility data were arc sine transformed prior to analysis (back-transformed data were used to calculate means and S.E.M). Menstrual phase (follicular, periovulatory and luteal), coagulum incidence (present and absent) and time of semen collection (10, 30 and $60 \mathrm{~min}$ ) were the main fixed effects. Males $(n=3)$, females $(n=5)$ and males within females $(n=15)$ were entered as both random and fixed effects, while semen aliquots in each collection time $(n=2)$, and replicated inseminations using the 
same male and female $(n=1-3$ per menstrual phase per coagulum incidence due to discarding some samples) were considered pure random effects. We used a Bonferroni procedure in post hoc paired comparisons between menstrual phases when contrasting significant main effects and interactions. We did multiple regressions followed by analysis of residuals to evaluate the relationship between percentages of intra-uterine collected FLM, SLM, NLM and IMM (averaged over times of collection) with vaginal $\mathrm{pH}$ and temperature measures, irrespective of menstrual phase. Significance in all the cases was set at $P \leq 0.05$. We used SPSS 15 (SPSS Inc., Chicago, IL, USA) to perform all the analyses.

\section{Declaration of interest}

We declare that there is no conflict of interest that could be perceived as prejudicing the impartiality of the research reported.

\section{Funding}

This work was supported by the Instituto Nacional de Psiquiatría Ramón de la Fuente Muñiz (Research Grant \# 3320-A).

\section{Acknowledgements}

The authors thank the two anonymous reviewers for their helpful suggestions, and Mrs Sally Packard for correcting and improving the English.

\section{References}

Baker RR \& Bellis MA 1993 Human sperm competition: ejaculate manipulation by females and a function for female orgasm. Animal Behaviour 6 887-909.

Bauman JE, Kolodny RC \& Webster SK 1982 Vaginal organic acids and hormonal changes. Fertility and Sterility 38 572-579.

Birkhead TR \& Pizzari T 2002 Postcopulatory sexual selection. Nature Reviews. Genetics 3 262-273.

Boskey ER, Telsch KM, Whaley KJ, Moench TR \& Cone RA 1999 Acid production by vaginal flora in vitro is consistent with the rate and extent of vaginal acidification. Infection and Immunity 67 5170-5175.

Boskey ER, Cone RA, Whaley KJ \& Moench TR 2001 Origins of vaginal acidity: high $\mathrm{D} / \mathrm{L}$ lactate ratio is consistent with bacteria being the primary source. Human Reproduction 16 1809-1813.

Campbell CJ, Aureli F, Chapman CA, Ramos-Fernández G, Matthews K, Russo SE, Suarez S \& Vick L 2005 Terrestrial behavior of Ateles spp. International Journal of Primatology 26 1039-1051.

Carr D, Usselman MC \& Acott TS 1985 Effects of pH, lactate, and viscoelastic drag on sperm motility: a species comparison. Biology of Reproduction 33 588-595.

Castle PE, Karp DA, Zeitlin L, García-Moreno B, Moench TR \& Whaley KJ 2002 Human monoclonal antibody stability and activity at vaginal $\mathrm{pH}$. Journal of Reproductive Immunology 56 61-76.

Clark LN \& Swanson JW 2005 Pervasive adaptive evolution in primate seminal proteins. PLoS Genetics $1335-342$.

Cooper TG 1998 Epididymis. In Encyclopedia of Reproduction, pp 1-17. Eds E Knobil \& JD Neill. San Diego: Academic Press.

Devine CM 1977 Copulatory plug restricted mating opportunities and reproductive competition among male garter snakes. Nature $\mathbf{2 6 7}$ 245-246.
Dixson AF 1998 Primate Sexuality: Comparative Studies of the Prosimians, Monkeys, Apes and Human Beings, Oxford: Oxford University Press.

Dixson AF \& Anderson MJ 2002 Sexual selection, seminal coagulation and copulatory plug formation in primates. Folia Primatologica 73 63-69.

Dixson AF \& Anderson MJ 2004 Sexual behavior, reproductive physiology and sperm competition in male mammals. Physiology and Behavior 83 $361-371$.

Donald A \& Dewsbury A 1988 A test of the role of copulatory plugs in sperm competition in deer mice (Peromyscus maniculatus). Journal of Mammalogy $69854-857$.

Dorus S, Evans PD, Wyckoff GJ, Choi SS \& Lahn BT 2004 Rate of molecular evolution of the seminal protein gene SEMG2 correlates with levels of female promiscuity. Nature Genetics 36 1326-1329.

Eberhard WG 1996 Female Control: Sexual Selection by Cryptic Female Choice. Princeton: Princeton University Press.

Eberhard WG 1998 Female roles in sperm competition. In Sperm Competition and Sexual Selection, pp 91-116. Eds TR Birkhead \& AP Möller. San Diego: Academic Press.

Estrada A, Luecke L, Van Belle S, Barrueta E \& Rosales Meda M 2004 Survey of black howler (Alouatta pigra) and spider (Ateles geoffroyi) monkeys in the Mayan sites of Calakmul and Yaxchilán, Mexico and Tikal, Guatemala. Primates 45 33-39.

Gago C, Pérez-Sánchez F, Yeung CH, Tablado L, Cooper TG \& Soler C 1999 Morphological characterization of ejaculated cynomolgous monkey (Macaca fascicularis) sperm. American Journal of Primatology 47 105-115.

Gomendio M, Harcourt A \& Roldán ERS 1998 Sperm competition in mammals. In Sperm Competition and Sexual Selection, pp 667-755. Eds TR Birkhead \& AP Möller. San Diego: Academic Press.

Gomendio M, Malo A, Garde J \& Roldan E 2007 Sperm traits and male fertility in natural populations. Reproduction 134 19-29.

Gundlach G \& Luttermann-Semmer E 1987 The effect of $\mathrm{pH}$ and temperature on the stability and enzymatic activity of prostatic acid phosphatase. Studies on the optimization of a continuous monitored determination of acid phosphatase. Journal of Clinical Chemistry and Clinical Biochemistry 25 441-446.

Harcourt AH, Harvey PH, Larson SG \& Short RV 1981 Testis weight, body weight and breeding system in primates. Nature 293 55-57.

Harper MJK 1994 In The Physiology of Reproduction, pp 123-187. Eds E Knobil \& JD Neill. New York: Raven Press.

Hernández-López L, Mayagoitia L, Esquivel-Lacroix C, Rojas-Maya S \& Mondragón-Ceballos R 1998 The menstrual cycle of the spider monkey (Ateles geoffroyi). American Journal of Primatology 44 183-195.

Hernández-López L, Cerezo-Parra G, Cerda-Molina AL, Pérez-Bolaños SC \& Mondragón-Ceballos R 2002a Digestion by trypsin enhances assessment of sperm parameters in the black-handed spider monkey (Ateles geoffroyi). Laboratory Primate Newsletter 41 4-6.

Hernández-López L, Cerezo-Parra G, Cerda-Molina AL, Pérez-Bolaños SC, Díaz-Sánchez V \& Mondragón-Ceballos R 2002b Sperm quality differences between the rainy and dry seasons in captive black-handed spider monkeys (Ateles geoffroyi). American Journal of Primatology $\mathbf{5 7}$ 35-41.

Hernández-López L, Cerda-Molina AL, Paéz-Ponce DL \& MondragónCeballos R 2008 Seasonal emission of seminal coagulum and in vivo sperm dynamics in the black-handed spider monkey (Ateles geoffroyi). Theriogenology 69 466-472.

Immler S 2008 Sperm competition and sperm cooperation: the potential role of diploid and haploid expression. Reproduction 135 275-283.

Khosrowbeygi A \& Zarghami N 2007 Levels of oxidative stress biomarkers in seminal plasma and their relationship with seminal parameters. $B M C$ Clinical Pathology 1 6-12.

de Lamiranda E 2007 Semenogelin, the main protein of the human semen coagulum, regulates sperm function. Seminars in Thrombosis and Hemostasis 33 60-68.

Lewis SE 2007 Is sperm evaluation useful in predicting human fertility? Reproduction 134 31-40.

Lilja H 1993 Structure, function, and regulation of the enzyme activity of prostate-specific antigen. Journal of Urology 11 188-191.

Malo AF, Garde JJ, Soler AJ, García AJ, Gomendio M \& Roldan ERS 2005 Male fertility in natural populations of red deer is determined by sperm velocity and the proportion of normal spermatozoa. Biology of Reproduction 72 822-829. 
McCulloch C \& Searle S 2001 Generalized, Linear and Mixed Models, New York: Wiley.

Mikhailichenko V \& Esipov A 2005 Peculiarities of semen coagulation and liquefaction in males from infertile couples. Fertility and Sterility $\mathbf{8 4}$ 256-259.

Olds-Clarke P 1996 How does poor motility alter sperm fertilizing ability. Journal of Andrology 17 183-186.

Olmsted SS, Khanna KV, Ng EM, Whitten ST, Johnson ON, Markham RB, Cone RA \& Moench TR 2005 Low pH immobilizes and kills human leucocytes and prevents transmission of cell-associated HIV in a mouse model. BMC Infectious Diseases 5 79-88.

Overstreet JW \& Cooper GW 1978 Sperm transport in the reproductive tract of the female rabbit. I. The rapid phase transport. Biology of Reproduction 19 101-114.

Papka R \& Williams S 1998 Vagina. In Encyclopedia of Reproduction, pp 961-968. Eds E Knobil \& JD Neill. San Diego: Academic Press.

Parga JA 2003 Plug displacement evidences sperm competition in Lemur catta. International Journal of Primatology 24 889-899.

Parker GA 1998 Sperm competition and the evolution of ejaculates: towards a theory base. In Sperm Competition and Sexual Selection, pp 3-54. Eds TR Birkhead \& AP Möller. San Diego: Academic Press.

Prins GS 1998 Semen. In Encyclopedia of Reproduction, pp 360-367. Eds E Knobil \& JD Neill. San Diego: Academic Press.

Robert M \& Gagnon C 1996 Purification and characterization of the active precursor of a human sperm motility inhibitor secreted by the seminal vesicles: identitiy with semenogelin. Biology of Reproduction $\mathbf{5 5}$ 813-821.

Rodriguez-Martinez H 2007 Role of the oviduct in sperm capacitation. Theriogenology 68 (Supplement 1) S138-S146.

De Rosa M, Boggia B, Amalfi B, Zarrilli S, Vita A, Colao A \& Lombardi G 2005 Correlation between seminal carnitine and functional spermatozoal characteristics in men with semen dysfunction of various origins. Drugs in R\&D 6 1-9.
Rossato M, Balercia G, Lucarelli G, Foresta C \& Mantero F 2002 Role of seminal osmolarity in the reduction of human sperm motility. International Journal of Andrology 25 230-235.

Satake N, Elliot RMA, Watson PF \& Holt WV 2006 Sperm selection and competition in pigs may be mediated by the differential motility activation and suppression of sperm subpopulations within the oviduct. Journal of Experimental Biology 209 1560-1572.

Sato I, Yoshikawa A, Ishiwari A \& Shimizu K 2007 Evaluation of urinary prostate-specific antigenic activity on the seasonality in male Japanese macaques (Macaca fuscaa fuscata). Journal of Andrology 28 821-826.

Scott MA \& Overstreet JW 1998 Sperm transport. In Encyclopedia of Reproduction, pp 610-615. Eds E Knobil \& JD Neill. San Diego: Academic Press.

Song GJ, Norkus EP \& Lewis V 2006 Relationship between seminal ascorbic acid and sperm DNA integrity in infertile men. International Journal of Andrology 29 569-575.

Suarez SS 2007 Interactions of spermatozoa with the female reproductive tract: inspiration for assisted reproduction. Reproduction, Fertility, and Development 19 103-110.

Suarez SS \& Pacey AA 2006 Sperm transport in the female reproductive tract. Human Reproduction 12 23-37.

WHO 1992 Laboratory Manual for the Examination of Human Sperm and Sperm Cervical Mucus Interaction, Cambridge: Cambridge University Press.

Received 25 March 2008

First decision 29 April 2008

Revised manuscript received 19 June 2008

Accepted 22 July 2008 